Check for updates

The BMJ, London, UK

Correspondence to: P Doshi Pdoshi@bmj.com

Cite this as: $B M / 2022 ; 376: 0102$ http://dx.doi.org/10.1136/bmi.0102

Published: 19 January 2022

\section{Covid-19 vaccines and treatments: we must have raw data, now}

\author{
Data should be fully and immediately available for public scrutiny
}

Peter Doshi, Fiona Godlee, Kamran Abbasi

In the pages of The BMJ a decade ago, in the middle of a different pandemic, it came to light that governments around the world had spent billions stockpiling antivirals for influenza that had not been shown to reduce the risk of complications, hospital admissions, or death. The majority of trials that underpinned regulatory approval and government stockpiling of oseltamivir (Tamiflu) were sponsored by the manufacturer; most were unpublished, those that were published were ghostwritten by writers paid by the manufacturer, the people listed as principal authors lacked access to the raw data, and academics who requested access to the data for independent analysis were denied. ${ }^{1-4}$

The Tamiflu saga heralded a decade of unprecedented attention to the importance of sharing clinical trial data. ${ }^{6}$ Public battles for drug company data, ${ }^{7}$ transparency campaigns with thousands of signatures, ${ }^{910}$ strengthened journal data sharing requirements, ${ }^{11} 12$ explicit commitments from companies to share data, ${ }^{13}$ new data access website portals, ${ }^{8}$ and landmark transparency policies from medicines regulators ${ }^{14}{ }^{15}$ all promised a new era in data transparency.

Progress was made, but clearly not enough. The errors of the last pandemic are being repeated. Memories are short. Today, despite the global rollout of covid-19 vaccines and treatments, the anonymised participant level data underlying the trials for these new products remain inaccessible to doctors, researchers, and the public-and are likely to remain that way for years to come. ${ }^{16}$ This is morally indefensible for all trials, but especially for those involving major public health interventions.

\section{Unacceptable delay}

Pfizer's pivotal covid vaccine trial was funded by the company and designed, run, analysed, and authored by Pfizer employees. The company and the contract research organisations that carried out the trial hold all the data. ${ }^{17}$ And Pfizer has indicated that it will not begin entertaining requests for trial data until May 2025, 24 months after the primary study completion date, which is listed on ClinicalTrials.gov as 15 May 2023 (NCT04368728).

The lack of access to data is consistent across vaccine manufacturers. ${ }^{16}$ Moderna says data "may be available ... with publication of the final study results in 2022." "Datasets will be available "upon request and subject to review once the trial is complete," which has an estimated primary completion date of 27 October 2022 (NCTo4470427).

As of 31 December 2021, AstraZeneca may be ready to entertain requests for data from several of its large phase III trials. ${ }^{19}$ But actually obtaining data could be slow going. As its website explains, "timelines vary per request and can take up to a year upon full submission of the request." 20

Underlying data for covid-19 therapeutics are similarly hard to find. Published reports of Regeneron's phase III trial of its monoclonal antibody therapy REGEN-COV flatly state that participant level data will not be made available to others. ${ }^{21}$ Should the drug be approved (and not just emergency authorised), sharing "will be considered.” For remdesivir, the US National Institutes of Health, which funded the trial, created a new portal to share data (https://accessclinicaldata.niaid.nih.gov/), but the dataset on offer is limited. An accompanying document explains: "The longitudinal data set only contains a small subset of the protocol and statistical analysis plan objectives."

We are left with publications but no access to the underlying data on reasonable request. This is worrying for trial participants, researchers, clinicians, journal editors, policy makers, and the public. The journals that have published these primary studies may argue that they faced an awkward dilemma, caught between making the summary findings available quickly and upholding the best ethical values that support timely access to underlying data. In our view, there is no dilemma; the anonymised individual participant data from clinical trials must be made available for independent scrutiny.

Journal editors, systematic reviewers, and the writers of clinical practice guideline generally obtain little beyond a journal publication, but regulatory agencies receive far more granular data as part of the regulatory review process. In the words of the European Medicine Agency's former executive director and senior medical officer, "relying solely on the publications of clinical trials in scientific journals as the basis of healthcare decisions is not a good idea ... Drug regulators have been aware of this limitation for a long time and routinely obtain and assess the full documentation (rather than just publications)." 22

Among regulators, the US Food and Drug Administration is believed to receive the most raw data but does not proactively release them. After a freedom of information request to the agency for Pfizer's vaccine data, the FDA offered to release 500 pages a month, a process that would take decades to complete, arguing in court that publicly releasing data was slow owing to the need to first redact sensitive information. ${ }^{23}$ This month, however, a judge rejected the FDA's offer and ordered the data be released at a rate of 55000 pages a month. The data are to be made available on the requesting organisation's website (https://phmpt.org/). 
In releasing thousands of pages of clinical trial documents, Health Canada and the EMA have also provided a degree of transparency that deserves acknowledgment. ${ }^{24} 25$ Until recently, however, the data remained of limited utility, with copious redactions aimed at protecting trial blinding. But study reports with fewer redactions have been available since September 2021, 2425 and missing appendices may be accessible through freedom of information requests.

Even so, anyone looking for participant level datasets may be disappointed because Health Canada and the EMA do not receive or analyse these data, and it remains to be seen how the FDA responds to the court order. Moreover, the FDA is producing data only for Pfizer's vaccine; other manufacturers' data cannot be requested until the vaccines are approved, which the Moderna and Johnson \& Johnson vaccines are not. Industry, which holds the raw data, is not legally required to honour requests for access from independent researchers.

Like the FDA, and unlike its Canadian and European counterparts, the UK's regulator-the Medicines and Healthcare Products Regulatory Agency-does not proactively release clinical trial documents, and it has also become delayed in posting information released in response to freedom of information requests on its website. $^{26}$

\section{Transparency and trust}

As well as access to the underlying data, transparent decision making is essential. Regulators and public health bodies could release details ${ }^{27}$ such as why vaccine trials were not designed to test efficacy against infection and spread of SARS-CoV-2. ${ }^{28} \mathrm{Had}$ regulators insisted on this outcome, countries would have learnt sooner about the effect of vaccines on transmission and been able to plan accordingly. ${ }^{29}$

Big pharma is the least trusted industry. ${ }^{30}$ At least three of the many companies making covid-19 vaccines have past criminal and civil settlements costing them billions of dollars. ${ }^{31}$ One pleaded guilty to fraud. ${ }^{31}$ Other companies have no pre-covid track record. Now the covid pandemic has minted many new pharma billionaires, and vaccine manufacturers have reported tens of billions in revenue. ${ }^{32}$

The BMJ supports vaccination policies based on sound evidence. As the global vaccine rollout continues, it cannot be justifiable or in the best interests of patients and the public that we are left to just trust "in the system," with the distant hope that the underlying data may become available for independent scrutiny at some point in the future. The same applies to treatments for covid-19.

Transparency is the key to building trust and an important route to answering people's legitimate questions about the efficacy and safety of vaccines and treatments and the clinical and public health policies established for their use.

Twelve years ago we called for the immediate release of raw data from clinical trials. ${ }^{1}$ We reiterate that call now. Data must be available when trial results are announced, published, or used to justify regulatory decisions. There is no place for wholesale exemptions from good practice during a pandemic. The public has paid for covid-19 vaccines through vast public funding of research, and it is the public that takes on the balance of benefits and harms that accompany vaccination. The public, therefore, has a right and entitlement to those data, as well as to the interrogation of those data by experts.

Pharmaceutical companies are reaping vast profits without adequate independent scrutiny of their scientific claims. ${ }^{33}$ The purpose of regulators is not to dance to the tune of rich global corporations and enrich them further; it is to protect the health of their populations. We need complete data transparency for all studies, we need it in the public interest, and we need it now.

Competing interests: We have read and understood BMJ policy on declaration of interests and declare that The BMJ is a co-founder of the AllTrials campaign. PD was one of the Cochrane reviewers studying influenza antivirals beginning in 2009, who campaigned for access to data. He also helped organise the Coalition Advocating for Adequately Licensed Medicines (CAALM), which formally petitioned the FDA to refrain from fully approving any covid-19 vaccine this year (docket FDA-2021-P-0786). PD is also a member of Public Health and Medical Professionals for Transparency, which has sued the FDA to obtain the Pfizer covid-19 vaccine data. The views and opinions do not necessarily reflect the official policy or position of the University of Maryland.

Provenance and peer review: Commissioned; externally peer reviewed.

Godlee F. We want raw data, now. BM/2009;339:b5405doi: 10.1136/bmj.b5405.

2 Godlee F, Clarke M. Why don't we have all the evidence on oseltamivir?BMJ2009;339:b5351. doi: 10.1136/bmj.b5351 pmid: 19995815

3 Cohen D. Complications: tracking down the data on oseltamivir. BMJ2009;339:b5387. doi: 10.1136/bmj.b5387 pmid: 19995818

4 Doshi P. Neuraminidase inhibitors - the story behind the Cochrane review. BMJ2009;339:b5164. doi: 10.1136/bmj.b5164 pmid: 19995813

5 Editorial Board. Full disclosure needed for clinical drug data. New York Times 2013 Jul 5. https://www.nytimes.com/2013/07/05/opinion/full-disclosure-needed-for-clinical-drug-data.html

6 Adams B. The pioneers of transparency. BMJ 2015;350:g7717. doi: 10.1136/bmj.g7717 pmid: 25555823

The BMJ. Open data campaign. https://www.bmj.com/open-data

8 Doshi P. From promises to policies: is big pharma delivering on transparency?BM/2014;348:g1615 doi: 10.1136/bmj.g1615 pmid: 24574476

$9 \quad$ All Trials. Supporters. https://www.alltrials.net/

10 To the civil society of Europe: support the Berlin Declaration 2012-stop hiding clinical trial data. https://www.change.org/p/to-the-civil-society-of-europe-support-the-berlin-declaration-2012stop-hiding-clinical-trial-data-2

11 Loder E, Groves T. The BMJ requires data sharing on request for all trials. BMJ 2015;350:h2373. doi: 10.1136/bmj.h2373 pmid: 25953153

12 Taichman DB, Sahni P, Pinborg A, etal. Data sharing statements for clinical trials. BMJ 2017;357:j2372. doi: 10.1136/bmj.j2372 pmid: 28584025

13 Pharmaceutical Research and Manufacturers of America, European Federation of Pharmaceutical Industries and Associations. Principles for responsible clinical trial data sharing. 2013. https://www.phrma.org/clinical-trials/phrma-principles-for-clinical-trial-data-sharing

14 Gøtzsche PC, Jørgensen AW. Opening up data at the European Medicines Agency. BMJ 2011;342:d2686. doi: 10.1136/bmj.d2686 pmid: 21558364

15 Lexchin J, Herder M, Doshi P. Canada finally opens up data on new drugs and devices. BMJ 2019;365:11825. doi: 10.1136/bmj.l1825 pmid: 30996020

16 Tanveer S, Rowhani-Farid A, Hong K, Jefferson T, Doshi P. Transparency of COVID-19 vaccine trials: decisions without data. BMJ Evid Based Med 2021:bmjebm-2021-111735. doi: 10.1136/bmjebm-2021-111735 pmid: 34373256

17 Thomas SJ, Moreira ED, JrKitchin N, etalC4591001 Clinical Trial Group. Safety and efficacy of the BNT162b2 mRNA covid-19 vaccine through 6 months. N Engl J Med 2021;385:1761-73. doi: 10.1056/NEJMoa2110345 pmid: 34525277

18 El Sahly HM, Baden LR, Essink B, etalCOVE Study Group. Efficacy of the mRNA-1273 SARS-CoV-2 vaccine at completion of blinded phase. N Engl J Med 2021;385:1774-85 doi: 10.1056/NEJMoa2113017 pmid: 34551225

19 Voysey M, Clemens SAC, Madhi SA, etalOxford COVID Vaccine Trial Group. Safety and efficacy of the ChAdOx1 nCoV-19 vaccine (AZD1222) against SARS-CoV-2: an interim analysis of four randomised controlled trials in Brazil, South Africa, and the UK. Lancet 2021;397:99-111. doi: 10.1016/S0140-6736(20)32661-1 pmid: 33306989

20 AstraZeneca. Clinical trials website. https://astrazenecagrouptrials.pharmacm.com/ST/Submission/Disclosure

21 Weinreich DM, Sivapalasingam S, Norton T, etalTrial Investigators. REGEN-COV antibody combination and outcomes in outpatients with covid-19. N Engl J Med 2021;385:e81. doi: 10.1056/NEJMoa2108163 pmid: 34587383

22 Eichler H-G, Rasi G. Clinical trial publications: a sufficient basis for healthcare decisions? Eur J Intern Med 2020;71:13-4. doi: 10.1016/j.ejim.2019.11.022 pmid: 31948774

23 Greene J. We'll all be dead before FDA releases full COVID vaccine record, plaintiffs say. Reuters 2021 Dec 13. https://www.reuters.com/legal/government/well-all-be-dead-before-fda-releasesfull-covid-vaccine-record-plaintiffs-say-2021-12-13/

24 Health Canada. Search for clinical information on drugs and medical devices. 2019 https://clinicalinformation.canada.ca/

25 European Medicines Agency. Online access to clinical data for medicinal products for human use. 2017. https://clinicaldata.ema.europa.eu/

26 Medicines and Healthcare Products Regulatory Agency. Freedom of Information responses from the MHRA. 2021. https://www.gov.uk/government/collections/freedom-of-information-responsesfrom-the-mhra-2021 
27 Mahase E. Covid-19: vaccine advisory committee must be more transparent about decisions, say researchers. BMJ2021;375:n2452. doi: 10.1136/bmj.n2452 pmid: 34620583

28 Doshi P. Will covid-19 vaccines save lives? Current trials aren't designed to tell us. BMJ 2020;371:m4037. doi: 10.1136/bmj.m4037 pmid: 33087398

29 lacobucci G. Covid-19: Focus should be on new vaccines rather than boosters, says WHO. BMJ 2022;376:0108doi: 10.1136/bmj.o108.

30 McCarthy J. Big pharma sinks to the bottom of US industry rankings. Gallup. 2019 https://news.gallup.com/poll/266060/big-pharma-sinks-bottom-industry-rankings.aspx

31 Outterson K. Punishing health care fraud-is the GSK settlement sufficient?. N Engl J Med 2012;367:1082-5. doi: 10.1056/NEJMp1209249 pmid: 22970920

32 Ziady H. Covid vaccine profits mint 9 new pharma billionaires. CNN 2021 May 21. https://www.cnn.com/2021/05/21/business/covid-vaccine-billionaires/index.html

33 Johnson RM, Doshi P, Healy D. Covid-19: Should doctors recommend treatments and vaccines when full data are not publicly available?BM/2020;370:m3260. doi: 10.1136/bmj.m3260 pmid: 32839164 